\title{
$N$-glycosylation and receptor tyrosine kinase signaling affect claudin-3 levels in colorectal cancer cells
}

\author{
AMELIA G. PÉREZ ${ }^{1}$, JÉSSICA ANDRADE-DA-COSTA ${ }^{1}$, WALDEMIR F. DE SOUZA ${ }^{1}$, \\ MICHELLE DE SOUZA FERREIRA ${ }^{1}$, MARIANA BORONI ${ }^{2}$, IVANIR M. DE OLIVEIRA ${ }^{3}$, \\ CARLOS A. FREIRE-NETO ${ }^{1}$, PRISCILA V. FERNANDES ${ }^{3}$, CRISTÓVÃO A. DE LANNA ${ }^{2}$, \\ PAULO THIAGO SOUZA-SANTOS ${ }^{4}$, JOSÉ A. MORGADO-DÍAZ ${ }^{1}$ and JULIO CESAR M. DE-FREITAS-JUNIOR ${ }^{1}$ \\ ${ }^{1}$ Cellular and Molecular Oncobiology Program; ${ }^{2}$ Bioinformatics and Computational Biology Laboratory; \\ ${ }^{3}$ Pathology Division, National Cancer Institute (INCA), Rio de Janeiro, RJ 20231-050; \\ ${ }^{4}$ Leprosy Laboratory, Oswaldo Cruz Institute (IOC), Rio de Janeiro, RJ 21041-361, Brazil
}

Received December 12, 2019; Accepted July 14, 2020

DOI: 10.3892/or.2020.7727

\begin{abstract}
Changes in protein levels in different components of the apical junctional complex occur in colorectal cancer (CRC). Claudin-3 is one of the main constituents of tight junctions, and its overexpression can increase the paracellular flux of macromolecules, as well as the malignant potential of CRC cells. The aim of this study was to investigate the molecular mechanisms involved in the regulation of claudin-3 and its prognostic value in CRC. In silico evaluation in each of the CRC consensus molecular subtypes (CMSs) revealed that high expression levels of CLDN3 (gene encoding claudin-3) in CMS2 and CMS3 worsened the patients' long-term survival, whereas a decrease in claudin-3 levels concomitant with a reduction in phosphorylation levels of epidermal growth factor
\end{abstract}

Correspondence to: Dr Julio Cesar M. De-Freitas-Junior, Cellular and Molecular Oncobiology Program, National Cancer Institute (INCA), 37 André Cavalcanti Street, 2th Floor, Rio de Janeiro, RJ 20231-050, Brazil

E-mail: jcjunior@inca.gov.br

Abbreviations: AJC, apical junctional complex; B3GNT8, $\beta-1,3-$ $N$-acetylglucosaminyltransferase 8; BRAF, V-Raf murine sarcoma viral oncogene homolog B; CLDN3, gene encoding claudin-3; CMS, consensus molecular subtypes; CRC, colorectal cancer; DPAGT1, dolichyl-phosphate $\mathrm{N}$-acetylglucosaminephosphotransferase $\quad 1$; EGFR, epidermal growth factor receptor; IGF1R, insulin-like growth factor 1 receptor; KRAS, Kirsten rat sarcoma viral oncogene homolog; L-PHA, phytohemagglutinin-L or Phaseolus vulgaris leucoagglutinin; MGAT5, $\alpha$-mannoside $\beta-1,6-N$-acetylglucosamin yltransferase; PLC, phospholipase C; PP2A, protein phosphatase 2; RTKs, receptor tyrosine kinases; STAT3, signal transducer and activator of transcription 3; ST6GAL1, ST6 $\beta$-galactoside $\alpha$-2,6-sialyltransferase; TJ, tight junction

Key words: receptor tyrosine kinase, claudin-3, $N$-glycan, colorectal cancer, consensus molecular subtype receptor (EGFR) and insulin-like growth factor 1 receptor (IGF1R) could be achieved by inhibiting $N$-glycan biosynthesis in CRC cells. We also observed that specific inactivation of these receptor tyrosine kinases (RTKs) led to a decrease in claudin-3 levels, and this regulation seems to be mediated by phospholipase C (PLC) and signal transducer and activator of transcription 3 (STAT3) in CRC cells. RTKs are modulated by their $N$-linked glycans, and inhibition of $N$-glycan biosynthesis decreased the claudin-3 levels; therefore, we evaluated the correlation between $N$-glycogenes and CLDN3 expression levels in each of the CRC molecular subtypes. The CMS1 (MSI immune) subtype concomitantly exhibited low expression levels of CLDN3 and $N$-glycogenes (MGAT5, ST6GAL1, and $B 3 G N T 8$ ), whereas CMS2 (canonical) exhibited high gene expression levels of $C L D N 3$ and $N$-glycogenes (ST6GALI and $B 3 G N T 8)$. A robust positive correlation was also observed between $C L D N 3$ and B3GNT8 expression levels in all CMSs. These results support the hypothesis of a mechanism integrating RTK signaling and $N$-glycosylation for the regulation of claudin-3 levels in CRC, and they suggest that CLDN3 expression can be used to predict the prognosis of patients identified as CMS2 or CMS3.

\section{Introduction}

Colorectal cancer (CRC) is one of the most commonly diagnosed cancers in both males and females. Accordingly, this disease is a public health issue and accounts for $8.5 \%$ of all cancer-related deaths worldwide (1). CRC progression occurs through a series of well-defined clinical and histopathological features, ranging from single precursor lesions through benign tumors (serrated or tubular adenoma) to malignant disease (2).

$\mathrm{CRC}$ is a heterogeneous disease represented by biologically diverse subtypes. One of the most recent gene expression-based subtypings of CRC has proposed four consensus molecular subtypes (CMSs), namely CMS1-microsatellite instability immune, CMS2-canonical, CMS3-metabolic, and CMS4-mesenchymal. Each of these CMSs shows distinguishing molecular disorders related to different clinical 
outcomes $(3,4)$; however, consensus molecular classification has not yet been used as a tool to guide clinical decisions. The constant development of molecular stratification strategies is also still necessary to reveal clinical potentials (5).

Regardless of the subtype, the disruption of the apical junctional complex (AJC), consisting of tight junctions (TJs) and adherens junctions, is frequently observed during CRC progression (6). The functionality of TJs, which constitute the barrier to the paracellular flow of macromolecules and ions, is regulated in part by the levels of its proteins $(7,8)$, and claudins in particular. Claudins are the main proteins in the regulation of TJs, and they also affect the stability of TJs via a fine-tuned mechanism $(9,10)$ involving changes in the subcellular localization and an imbalance (both overexpression and downregulation) in claudin levels. For example, dysregulation of claudin-3 is often observed in CRC (11). Claudin-3 overexpression destabilizes the TJs, causing an increase in transepithelial resistance and the paracellular flux of macromolecules leading to induction of cell migration and colony formation that can be either dependent or independent of anchorage (12).

Previous studies have also demonstrated that the stability of TJs is regulated by glycoproteins, such as receptor tyrosine kinases (RTKs) and E-cadherin (13-15), but the regulatory role of $N$-linked glycans in this process is poorly understood. Pioneering work using siRNA to DPAGT1 (the gene that encodes the enzyme that initiates the synthesis of the dolichol lipid-linked oligosaccharide precursor for protein $N$-glycosylation) showed that inhibition of $N$-glycosylation promotes the assembly of TJs through the recruitment of the PP2A protein (a negative regulator of TJ biogenesis) to adherens junctions (16), thereby suggesting a role for $N$-glycans in TJ stability. Indeed, the functionality of RTKs is finely tuned by the $N$-glycans attached to its extracellular domain.

Several studies have demonstrated that $N$-glycosylation contributes to ligand binding, kinase activity, and the determination of the proper conformation of the RTKs (17-20). For example, $\beta 1,6$-GlcNAc-branching $N$-glycans are synthesized by MGAT5 (also known as GnT-V; Fig. S1) and are inserted onto RTKs. Their presence promotes the binding of this branched structure to galectins to form molecular 'lattices' that prevent glycoprotein receptor endocytosis and lead to the persistence of cancer-related signaling (21). However, a mechanism that would integrate RTK signaling and $\mathrm{N}$-glycosylation with the regulation of claudin-3 levels in CRC remains to be established.

In the present study, we demonstrated that the high expression levels of CLDN3 in CRC worsened the patients' long-term survival. We also showed that inhibition of $N$-glycan biosynthesis in CRC cells led to a decrease in the levels of claudin-3 and, concomitantly, to a reduction in phosphorylation levels of epidermal growth factor receptor (EGFR) and insulin-like growth factor 1 receptor (IGF1R). We report that specific inactivation of RTKs also leads to a decrease in claudin-3 levels, and we provide evidence that the regulation of claudin-3 levels by changes in RTK signaling can be mediated by phospholipase C (PLC) and signal transducer and activator of transcription 3 (STAT3) in CRC cells. We therefore evaluated the correlation between $N$-glycogenes and $C L D N 3$ expression levels in each of the CRC molecular subtypes, since $N$-glycans are known to regulate RTKs. CMS1 (MSI immune) was the subtype that concomitantly exhibited low expression levels of $C L D N 3$ and $N$-glycogenes (MGAT5, ST6GAL1, and B3GNT8), whereas CMS2 (canonical) exhibited high gene expression levels of $C L D N 3$ and $N$-glycogenes (ST6GAL1 and B3GNT8). A robust positive correlation was also detected between $C L D N 3$ and $B 3 G N T 8$ expression levels in all four CMS. Taken together, our results support the hypothesis that $N$-glycans play a role in the regulation of RTKs, claudin-3, and TJs, thereby providing a better understanding of CRC biology.

\section{Materials and methods}

Chemicals and antibodies. The rabbit monoclonal antibodies used here included anti-pEGFR (Tyr 1068, cat. no. 2234), anti-EGFR (cat. no. 2646), anti-p-IR/p-IGF1R (Tyr 1150, 1151/Tyr 1135, 1136, cat. no. 3024), anti-IGF1R (cat. no. 3027), anti-pAKT (Ser 473, cat. no. 9271), anti-AKT (cat. no. 4691) and anti- $\alpha$-tubulin (cat. no. 2144) and were purchased from Cell Signaling Technology, Inc. Rabbit polyclonal antibodies anti-claudin-3 (cat. no. 34-1700), anti-occludin (cat. no. 33-1500) and anti-ZO1 (cat. no. 33-9100) were obtained from Thermo Fisher Scientific, Inc. Anti-mouse GAPDH monoclonal antibody (cat. no. 32233) were obtained from Santa Cruz Biotechnology, Inc. Secondary peroxidase-conjugated anti-mouse (cat. no. 2304) and anti-rabbit (cat. no. 9169) were purchased from Sigma-Aldrich (Merck KGaA). Fluorescein-conjugated Phaseolus vulgaris lectin (L-PHA lectin) was purchased from Vector Laboratories. Alexa Fluor 488-conjugated anti-rabbit secondary antibody (cat. no. 11008) was obtained from Molecular Probes (Thermo Fisher Scientific, Inc.). The tunicamycin A1 homolog (Tun), H-89 (a PKA inhibitor), PD 153035 (an EGFR inhibitor), forskolin (a PKA activator), and Ly294002 (a PI3K inhibitor) were purchased from Sigma-Aldrich (Merck KGaA). OSI906 (an IGF1R inhibitor) was purchased from Selleck Chemicals. PD98059 (a MEK1 inhibitor) was purchased from Cell Signaling Technology, Inc. U73122 (an inhibitor of PLC-dependent processes) was obtained from Cayman Chemical Co., while STA-21 (a STAT3 inhibitor) was obtained from Santa Cruz Biotechnology, Inc. Ruthenium red was purchased from Ted Pella Inc.

Cell culture and treatments. CRC cell lines (Caco-2, HCT-116, and HT-29) were obtained from the American Type Culture Collection (ATCC) and were authenticated using their short tandem repeat (STR) profiles. Cells were cultured at $37^{\circ} \mathrm{C}$ in a humidified atmosphere of $5 \% \mathrm{CO}_{2} /$ air in Dulbecco's modified Eagle's medium (DMEM, Thermo Fisher Scientific, Inc.) supplemented with $10 \%$ heat-inactivated fetal bovine serum (FBS) (Thermo Fisher Scientific, Inc.), penicillin G (60 mg/l), and streptomycin $(100 \mathrm{mg} / \mathrm{l})$. For experimental purposes, the cells were seeded in culture flasks or on plates, glass coverslips, or Transwell polycarbonate filters with a $0.4-\mu \mathrm{m}$ pore size (Corning, Inc.). After reaching $80 \%$ confluence, the cells were treated with the appropriate drugs for $24 \mathrm{~h}$. The drugs used for the different assays were tunicamycin at $0.25,0.50$, 0.75 , and $1 \mu \mathrm{g} / \mathrm{ml}$; PD153035 at 1,10 , and $20 \mu \mathrm{g} / \mathrm{ml}$; OSI906 at 2,4 , and $8 \mu \mathrm{g} / \mathrm{ml} ; \mathrm{U} 73122$ at 7, 14, and $21 \mu \mathrm{g} / \mathrm{ml}$; PD98059 at 7, 14, and $21 \mu \mathrm{g} / \mathrm{ml}$; LY294002 at 2, 4, and $6 \mu \mathrm{g} / \mathrm{ml}$; STA-21 
at 3, 4, 5, 6, and $7.5 \mu \mathrm{g} / \mathrm{ml} ; \mathrm{H}-89$ at $9 \mu \mathrm{g} / \mathrm{ml}$; and forskolin at $4 \mu \mathrm{g} / \mathrm{ml}$.

Tissue samples. Well-differentiated or moderately differentiated human colorectal specimens and mucinous adenocarcinomas were obtained from the surgical resections of 14 Brazilian patients (5 males and 9 females, aged $64 \pm 10$ years) from the Brazilian National Cancer Institute after patient consent. These samples were collected from February 2013 to June 2016. In all cases, control specimens were collected from the accompanying normal mucosa, $5-10 \mathrm{~cm}$ away from the carcinoma. All samples were evaluated by a board-certified pathologist. The cancer tissue and normal epithelium samples destined for use in immunoblotting were immediately frozen at $-80^{\circ} \mathrm{C}$. The study was carried out with the approval of the National Cancer Institute Ethics Committee ( $n^{\circ}$ 84/04). Clinicopathological features are listed in Table SI.

Western blotting. Cell cultures and homogenized tissue samples were washed with phosphate-buffered saline (PBS) and then lysed in a solution containing $1 \%$ Triton X-100, 1\% NP40, a protease inhibitor cocktail ( 1 tablet $/ 50 \mathrm{ml}$ buffer; Roche), and a phosphatase inhibitor cocktail (Sigma-Aldrich; Merck KGaA, 1:100 dilution). Total protein was quantified using a bicinchoninic acid (BCA) protein assay kit (Bio-Rad Laboratories, Inc.). For western blotting, the samples (30 $\mu \mathrm{g}$ of protein per lane) were subjected to SDS-PAGE (ranging from 7.5 to 13\%) and the separated proteins were transferred to a nitrocellulose membrane. The blots were then probed with primary (dilute solutions 1:1,000) and peroxidase-conjugated secondary (dilute solutions 1:40,000) antibodies or biotinylated lectins (Vector Laboratories). The proteins were visualized using an ECL chemiluminescence kit (GE Healthcare). Immunoreactive bands from lectin blots were then visualized using the Vector stain ABC kit (Vector Laboratories). The protein or carbohydrate levels were quantified by densitometry using LabWorks 4.6 software (Bio-Rad Laboratories, Inc.). The measurements were obtained from sub-exposed photographic films after the chemiluminescence reaction, and the values were normalized to the amount of a housekeeping protein (GAPDH or tubulin). Differences in protein levels were evaluated using ANOVA followed by the Dunnett post hoc test.

Lectin labeling by flow cytometry. Upon reaching $70 \%$ confluence, the cells were washed, collected from the plates, and fixed with paraformaldehyde (4\%) for $8 \mathrm{~min}$ at room temperature (RT). The cells were then washed, blocked with bovine serum albumin (4\%) (Sigma-Aldrich; Merck KGaA) for $30 \mathrm{~min}$, and centrifuged at $1,500 \mathrm{x}$ g for $3 \mathrm{~min}$. Fluorescein-conjugated L-PHA lectin was then added at a concentration of 5 or $2.5 \mu \mathrm{g} / \mathrm{ml}$. After incubation for $20 \mathrm{~min}$ at RT, the cells were collected by centrifugation and washed three times with PBS. Finally, $1 \times 10^{4}$ cells were analyzed by flow cytometry (FASCalibur; BD Biosciences). Unstained cells were used as negative controls for lectin recognition. Fluorescence histograms and median fluorescence data were created and analyzed with CellQuest Pro software (version 5.1.1; BD Biosciences).

Immunofluorescence and confocal microscopy. Cells were grown on glass coverslips until they reached $70 \%$ confluence.
The cell monolayers were washed with PBS, fixed with methanol for $20 \mathrm{~min}$ at $-20^{\circ} \mathrm{C}$, and then rehydrated with PBS/CM (PBS containing $100 \mathrm{mM} \mathrm{CaCl}_{2}$ and $100 \mathrm{mM}$ $\mathrm{MgCl}_{2}, \mathrm{pH} 8.0$ ) and blocked with $0.2 \%$ bovine serum albumin (BSA) for $60 \mathrm{~min}$. The cells were then incubated overnight with anti-claudin-3 (1:40 dilution), washed with PBS, and incubated for $1 \mathrm{~h}$ with Alexa Fluor 488-conjugated rabbit secondary antibody (1:500 dilution). Finally, all coverslips were incubated with DAPI and then washed and assembled using n-propyl gallate (Sigma-Aldrich; Merck KGaA). Images were acquired using an FV10i-O laser confocal microscope (Olympus) with constant laser intensity. The fluorescence intensity in both the cytoplasm and cell membrane was quantified using ICY Bioimage Analysis software (version 2.0.3.0; Institut Pasteur-France Bioimaging). For this purpose, an intensity-based line was used to measure the fluorescence in an area that included the junction between two cells.

Transmission electron microscopy. Cells were cultured on Transwell polycarbonate filters (Corning, Inc.) and fixed for $60 \mathrm{~min}$ on the apical side of the monolayer with a solution containing $2.5 \%$ glutaraldehyde, $1 \%$ freshly prepared paraformaldehyde, $8 \%$ sucrose, $2 \mathrm{mM} \mathrm{CaCl}$, and $6 \mathrm{mg} / \mathrm{ml}$ ruthenium red in $0.1 \mathrm{M}$ cacodylate buffer, $\mathrm{pH}$ 7.4. After washing with cacodylate buffer containing ruthenium red for $10 \mathrm{~min}$, the cells were postfixed with $1 \% \mathrm{OsO}_{4}$ and $6 \mathrm{mg} / \mathrm{ml}$ ruthenium red in cacodylate buffer for $45 \mathrm{~min}$. The cell monolayers were then washed with cacodylate buffer, dehydrated with an acetone series, and embedded in Epon resin. Ultrathin sections $(70 \mathrm{~nm})$ were stained with lead citrate and observed with a Zeiss CEM-900 transmission electron microscope (Carl Zeiss).

CMS subtyping and gene expression level analysis. The CRC molecular subtype classifier (4) was downloaded and applied to 644 primary human colorectal cancer samples using the RNA-Seq data from The Cancer Genome Atlas (TCGA) project database. Clinical-pathological and RNA-Seq data were obtained using the R package TCGABiolinks (22). The expression levels of $C L D N 3$ and related glycogenes (MGAT5, ST6GAL1, and B3GNT8) were then analyzed in the tumor samples previously classified according to their specific CMS, as well as in 51 normal samples, also from the TCGA database. Differences in gene expression were evaluated by Kruskal-Wallis test followed by pairwise comparisons using Dunn's test to compare rank means between each subgroup. All analyses and plots were performed in the R environment.

Clinical outcome analysis. The influence of the gene expression levels in clinical outcomes was determined by classifying the tumor samples into high or low groups according to the gene expression pattern. The data were divided into three sections (tertiles), and the upper and lower thirds were considered the high and low groups, respectively. The overall survival over six years was then analyzed within these low and high expression categories for all samples or by molecular subtype. Survival analyses were carried out using the 'survival' package for R.

Statistical analysis. All statistical analyses from in vitro assays were performed using the GraphPad Prism 5 software 

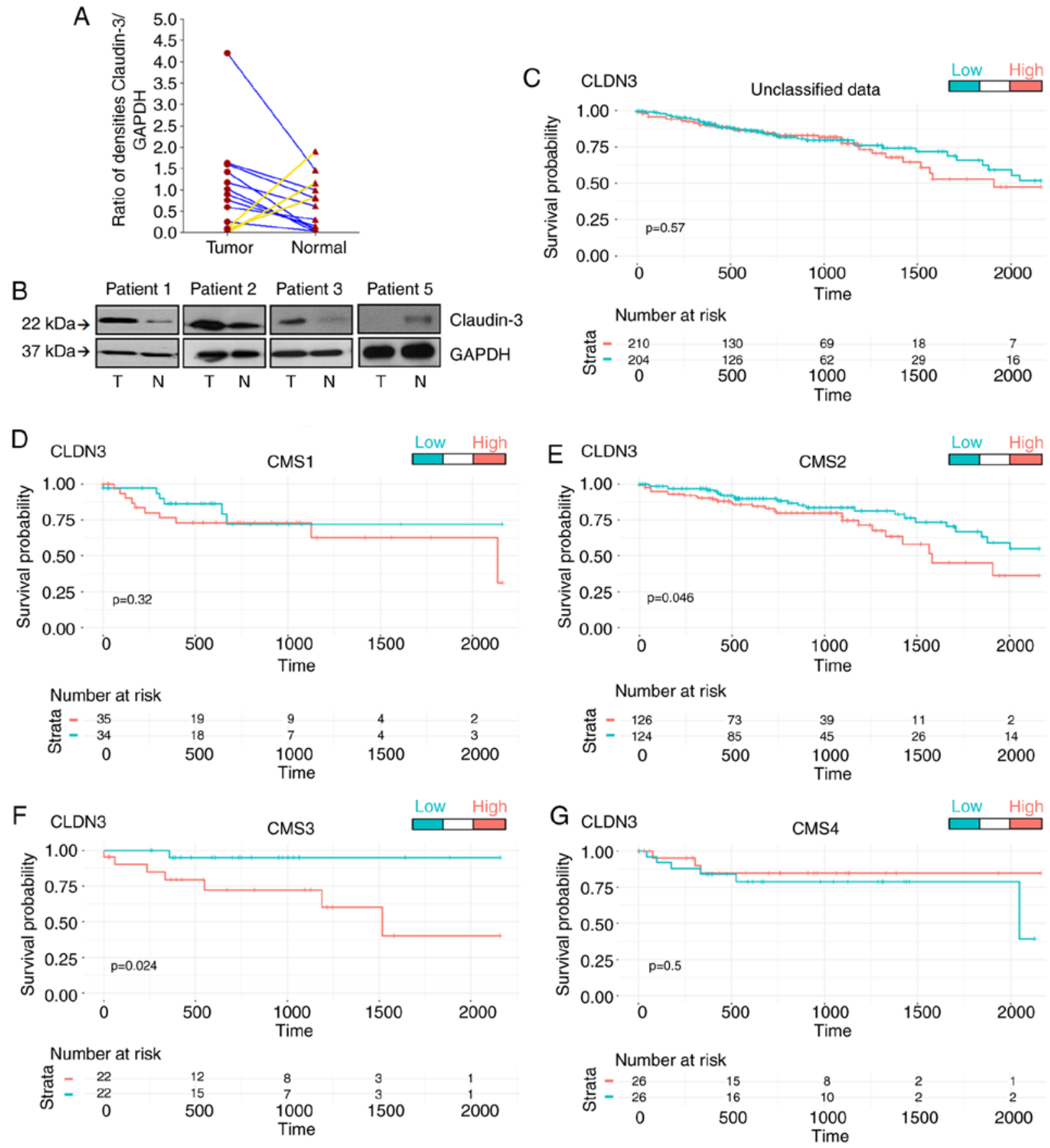

Figure 1. Claudin-3 protein levels in CRC samples and survival features of molecular subtypes substratified by CLDN3 expression levels. (A and B) Samples of adjacent normal tissue $(\mathrm{N})$ and tumor tissue $(\mathrm{T})$ were obtained and processed for further analysis of claudin-3 levels by western blotting ( $\mathrm{n}=14)$. Results of four representative patients are shown. The line graph represents the increase (blue) or decrease (yellow) in the ratio of claudin-3 densitometry units normalized by endogenous protein control (GAPDH) in tumor and normal samples of each patient. Prognostic value of $C L D N 3$ expression (upper and lower tertiles) in (C) unclassified data (n=414) and within (D) CMS1 (n=69), (E) CMS2 (n=250), (F) CMS3 ( $=44)$, and (G) CMS4 (n=52). CRC, colorectal cancer; CLDN3, gene encoding claudin-3.

(GraphPad Software). Differences were considered statistically significant at a P-value $<0.05$.

\section{Results}

Identification of colorectal cancer intra-CMS subgroups by expression analysis of CLDN3. We first analyzed claudin-3 levels in CRC samples and adjacent normal tissue and were able to identify two distinct subgroups of tumors: Those with high levels and those with low levels of claudin-3 protein (Fig. 1A and B). We then performed an in silico analysis using $644 \mathrm{CRC}$ samples from the TCGA database to assess the expression levels of $C L D N 3$. The possibility that the expression levels of $C L D N 3$ could affect the overall survival of CRC patients was tested by classifying the expression values as 'high' or 'low' using the following strategy: Data were divided into tertiles, and the values were defined as 'high' or 'low' only when they were in the tertiles with the highest or lowest values, respectively. The overall survival was calculated according to the expression 
A

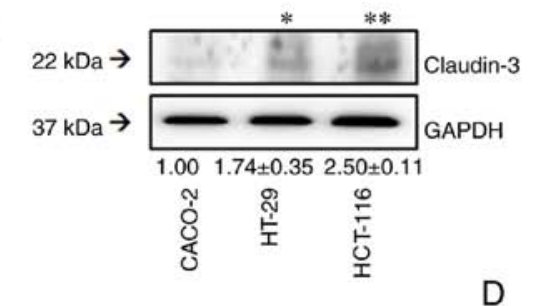

B
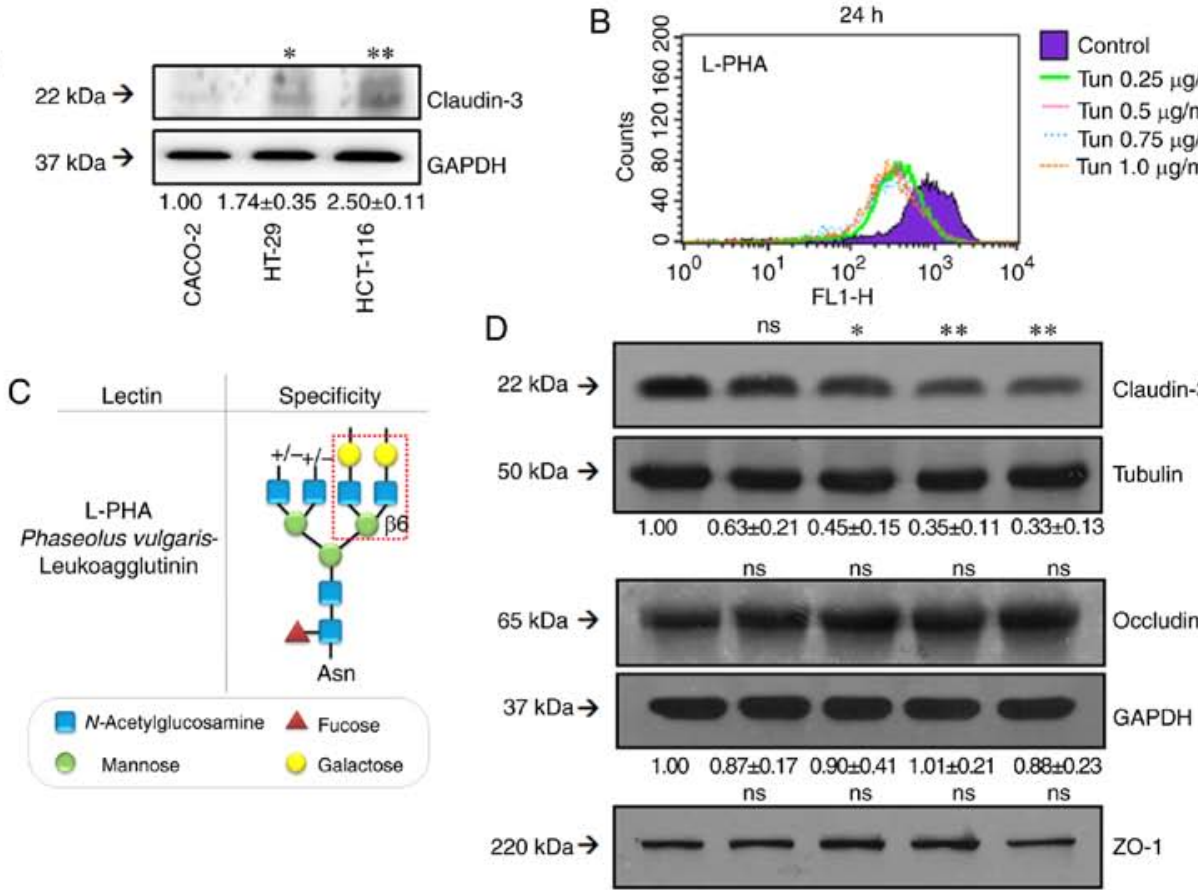

$50 \mathrm{kDa} \rightarrow$

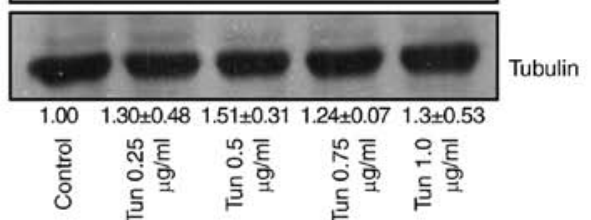

$\mathrm{E}$

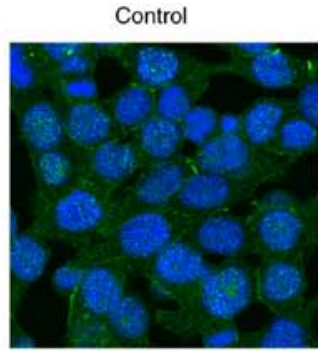

Tun $0.25 \mu \mathrm{g} / \mathrm{ml}$

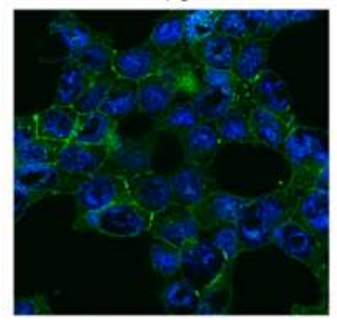

Tun $0.5 \mu \mathrm{g} / \mathrm{ml}$
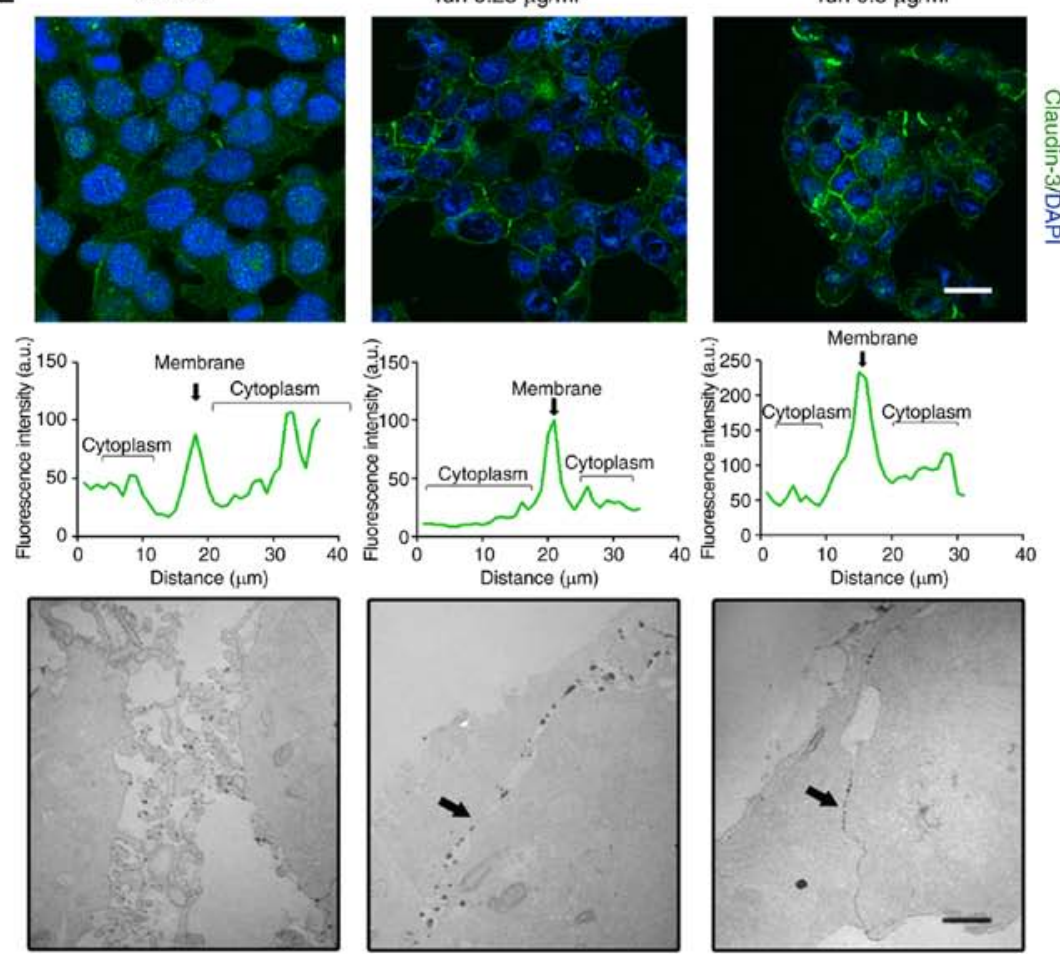

Figure 2. Effects of $N$-glycan biosynthesis inhibition on TJ stability. (A) Cell lysates from Caco-2, HT-29, and HCT-116 cells were analyzed by western blotting for claudin-3. (B) HCT-116 cells were treated with different concentrations of tunicamycin for $24 \mathrm{~h}$. After treatment, the cells were incubated with FITC-conjugated lectin L-PHA and analyzed by flow cytometry. The histograms of fluorescence were generated by the Cell Quest software: control (purple); $0.25 \mu \mathrm{g} / \mathrm{ml}$ (green); $0.5 \mu \mathrm{g} / \mathrm{ml}$ (pink); $0.75 \mu \mathrm{g} / \mathrm{ml}$ (blue); and $1 \mu \mathrm{g} / \mathrm{ml}$ (orange). (C) Lectin L-PHA specificity. (D) Cell lysates were obtained after $24 \mathrm{~h}$ treatment with tunicamycin and analyzed by western blotting for claudin-3, occludin, and ZO-1. Tubulin was used as an endogenous protein control. (E, upper panel) Cell monolayers were fixed and stained for claudin-3 (green) and nuclei (blue) (DAPI). Representative images were obtained by confocal microscopy. The graphs represent the fluorescence intensity in cytosolic and membrane regions of neighboring cells. Scale bar, $10 \mu \mathrm{m}$. (E, lower panel) Cells were cultured in filters of Transwell polycarbonate, and the functionality of TJs was analyzed by transmission electron microscopy (MET) using ruthenium red as a tracer. The images are representative of ultrathin sections of treated and control cells. Black arrows indicate the cell-cell contact. Scale bar, $2 \mu \mathrm{m}$. The numerical values represent densitometric units \pm standard error $(\mathrm{n}=3)$. ns, not significant $(\mathrm{P}>0.05) ;{ }^{*} \mathrm{P}<0.05 ;{ }^{* *} \mathrm{P}<0.01$; ANOVA. Tun, tunicamycin; TJ, tight junction; L-PHA, phytohemagglutinin-L or Phaseolus vulgaris leucoagglutinin. 


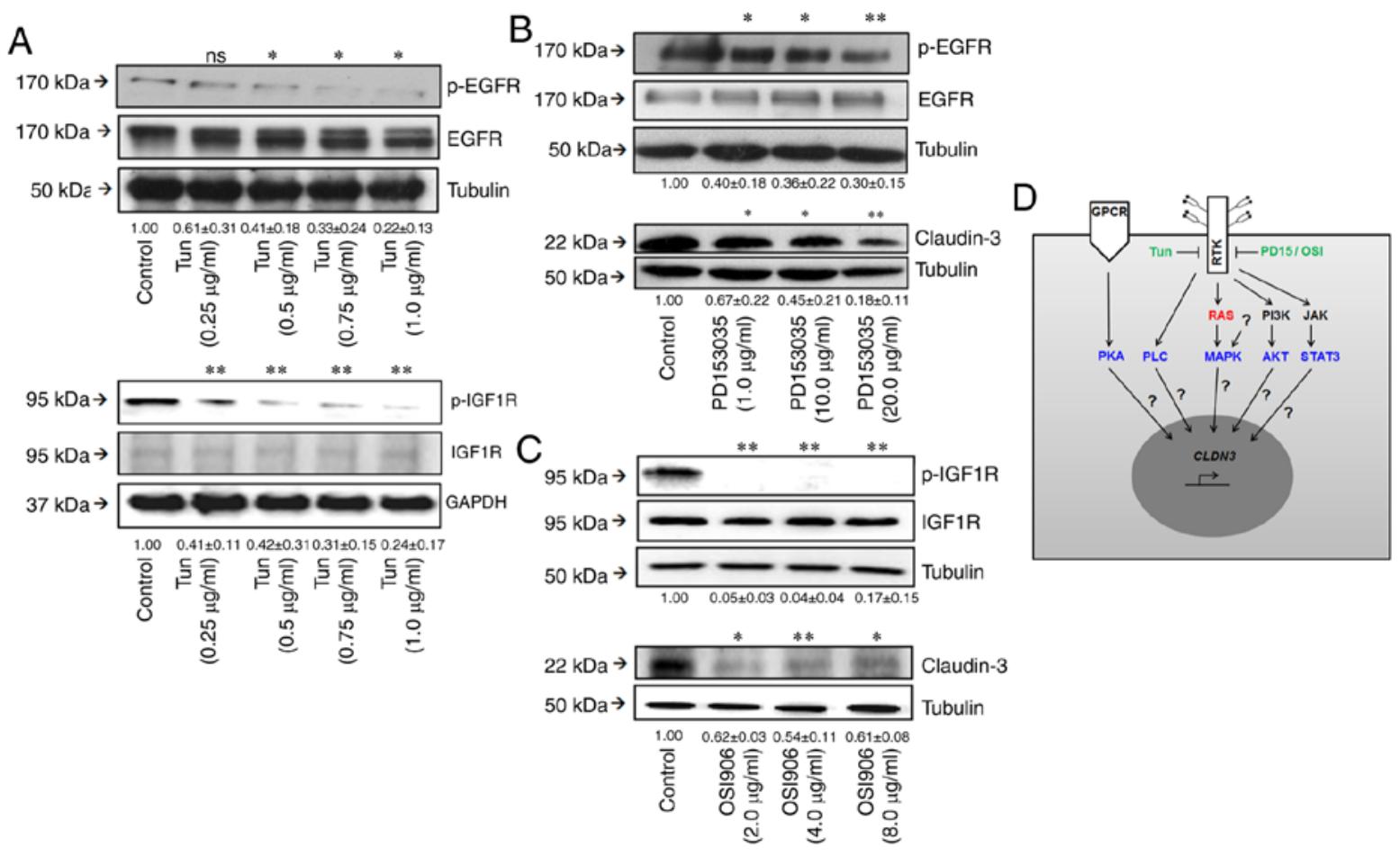

E

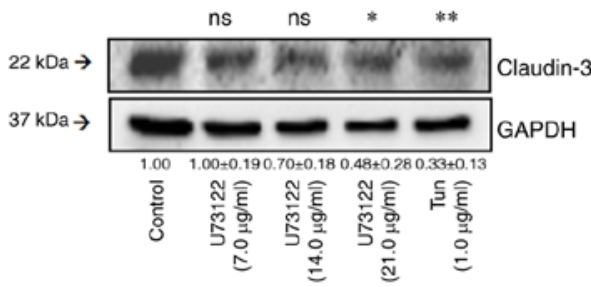

G

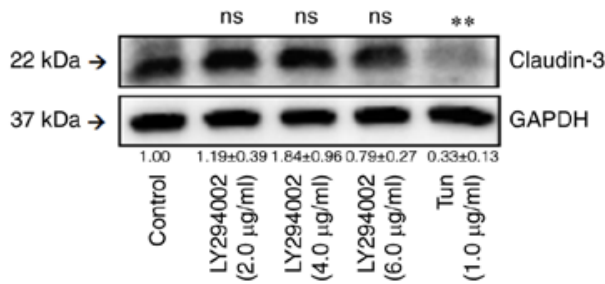

I

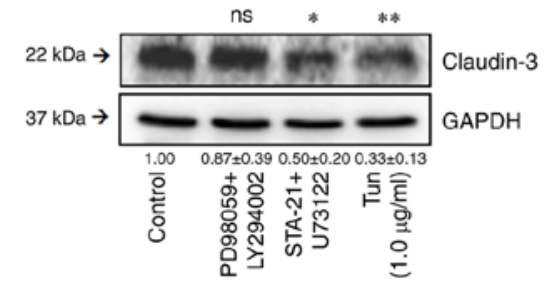

$\mathrm{F}$

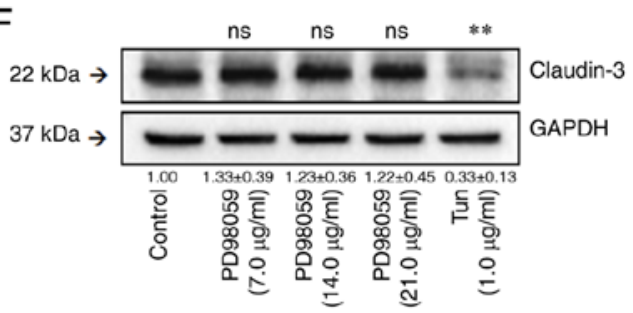

$\mathrm{H}$

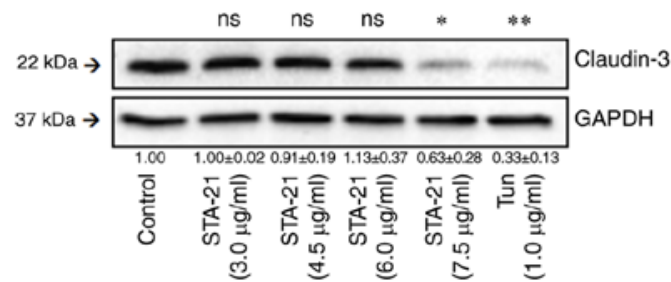

J

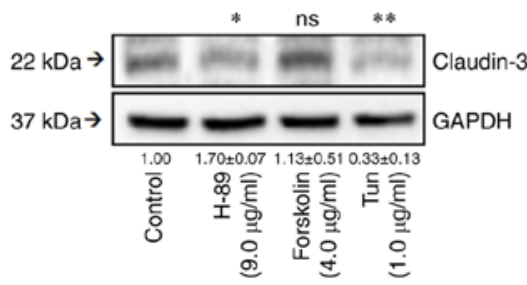

Figure 3. Effects of inhibition of $\mathrm{N}$-glycan biosynthesis on RTK functionality. (A) After treatment with tunicamycin, cell lysates were obtained and analyzed by western blotting for p-EGFR, EGFR, p-IGF1R, and IGF1R. (B and C) Cells were treated with different concentrations of PD153035 or OSI906 for $24 \mathrm{~h}$, and then levels of RTK phosphorylation and claudin-3 were assessed by western blotting. (D) Illustration showing RTK-related or non-RTK-related pathways, as well as on the relationship of this regulatory network with the regulation of $C L D N 3$ expression. (E-H) Effects of specific inhibitors on claudin-3 levels. Cells were treated with different concentrations of (E) U73122 (an inhibitor of PLC-dependent processes), (F) PD98059 (a MEK1 inhibitor), (G) Ly294002 (a PI3K inhibitor), and (H) STA-21 (a STAT3 inhibitor) for $24 \mathrm{~h}$, and then levels of claudin-3 were assessed by western blotting. (I) Cells were treated with paired combinations of inhibitors: PD98059 $(21 \mu \mathrm{g} / \mathrm{ml})$ and Ly294002 $(6 \mu \mathrm{g} / \mathrm{ml})$, or STA-21 $(7.5 \mu \mathrm{g} / \mathrm{ml})$ and U73122 $(21 \mu \mathrm{g} / \mathrm{ml})$. (J) Cells were treated with Forskolin or H-89 (a PKA inhibitor) for $24 \mathrm{~h}$, and then levels of claudin-3 were assessed by western blotting. The numerical values represent densitometric units \pm standard error $(\mathrm{n}=3)$. $\mathrm{ns}$, not significant $(\mathrm{P}>0.05) ;{ }^{*} \mathrm{P}<0.05 ;{ }^{* *} \mathrm{P}<0.01$; ANOVA. Tun, tunicamycin; RTKs, receptor tyrosine kinases; EGFR, epidermal growth factor receptor; IGF1R, insulin-like growth factor 1 receptor; $\mathrm{p}-$, phosphorylated.

levels of $C L D N 3$ in the unclassified data (Fig. 1C), as well as in data classified into the four different molecular subtypes of CRC (Fig. 1D-G). This strategy revealed that high expression levels of $C L D N 3$ in CMS2 and CMS3 worsened the patients' long-term survival (Fig. 1E and F). Taken together, these data demonstrated that analysis of 

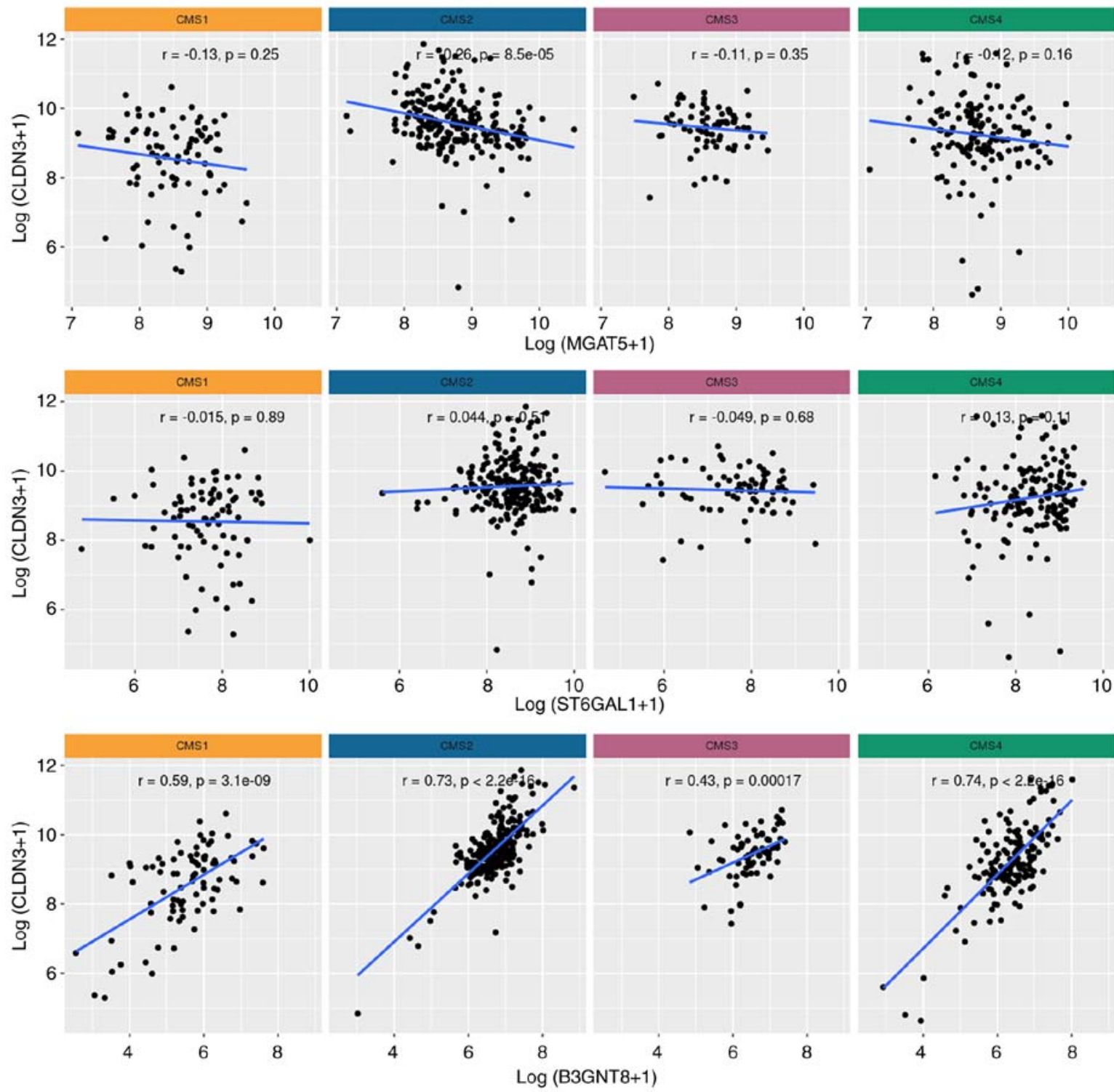

Figure 4. Correlation analyses between $C L D N 3$ and MGAT5, ST6GAL1, and B3GNT8 within the CMS. The correlation graphs represent the relationship between gene expression data from The Cancer Genome Atlas (TCGA) project database that were later classified for stratification as consensus molecular subtypes (CMSs). $C L D N 3$, gene encoding claudin-3; MGAT5, $\alpha$-mannoside $\beta$-1,6- $N$-acetylglucosaminyltransferase; ST6GAL1, ST6 $\beta$-galactoside $\alpha$-2,6-sialyltransferase; $B 3 G N T 8, \beta-1,3-N$-acetylglucosaminyltransferase 8 .

CLDN3 expression was useful for clearly separating the CMS2/CMS3 populations into two groups with distinct clinical outcomes. The data also showed that verification of the expression profile of specific genes within the CRC molecular subtypes represented an appealing strategy for identifying intra-CMS subgroups.

Inhibition of $\mathrm{N}$-glycan biosynthesis decreases the protein levels of claudin-3 and induces its redistribution in CRC cells. We first evaluated claudin-3 levels in different CRC cell lines and found that HCT-116 cells had the highest level of this protein among the cells analyzed (Fig. 2A). Interestingly, these undifferentiated CRC cells had previously demonstrated a weaker cell-cell adhesion phenotype than differentiated cells when the complex $N$-glycan levels in HCT-116 was increased (23). We therefore chose HCT-116 cells for subsequent investigations of the role of $\mathrm{N}$-glycans in TJ stability.
We determined that inhibition of $N$-glycosylation with low doses of tunicamycin (Tun) for $24 \mathrm{~h}$ resulted in the expected decrease in the levels of complex $N$-glycans on the surfaces of the treated cells (Fig. 2B), as verified by labeling with L-PHA lectin (Fig. 2C). We then used western blotting to determine the effect of tunicamycin treatment on TJ component levels [i.e., claudin-3, zonula occludens-1 (ZO-1), and occludin levels]. We observed that treatment with tunicamycin decreased the claudin-3 levels but did not affect the levels of other evaluated protein constituents (Fig. 2D). Treatment with tunicamycin also promoted a reorganization of the subcellular localization of claudin-3, characterized by an increase of its levels on the cell membrane (Fig. 2E, upper panel).

We also assessed permeability to ruthenium red to investigate whether changes in claudin-3 localization, induced by the inhibition of $\mathrm{N}$-glycosylation, could affect the functionality of the TJs. Transmission electron microscopy observations 

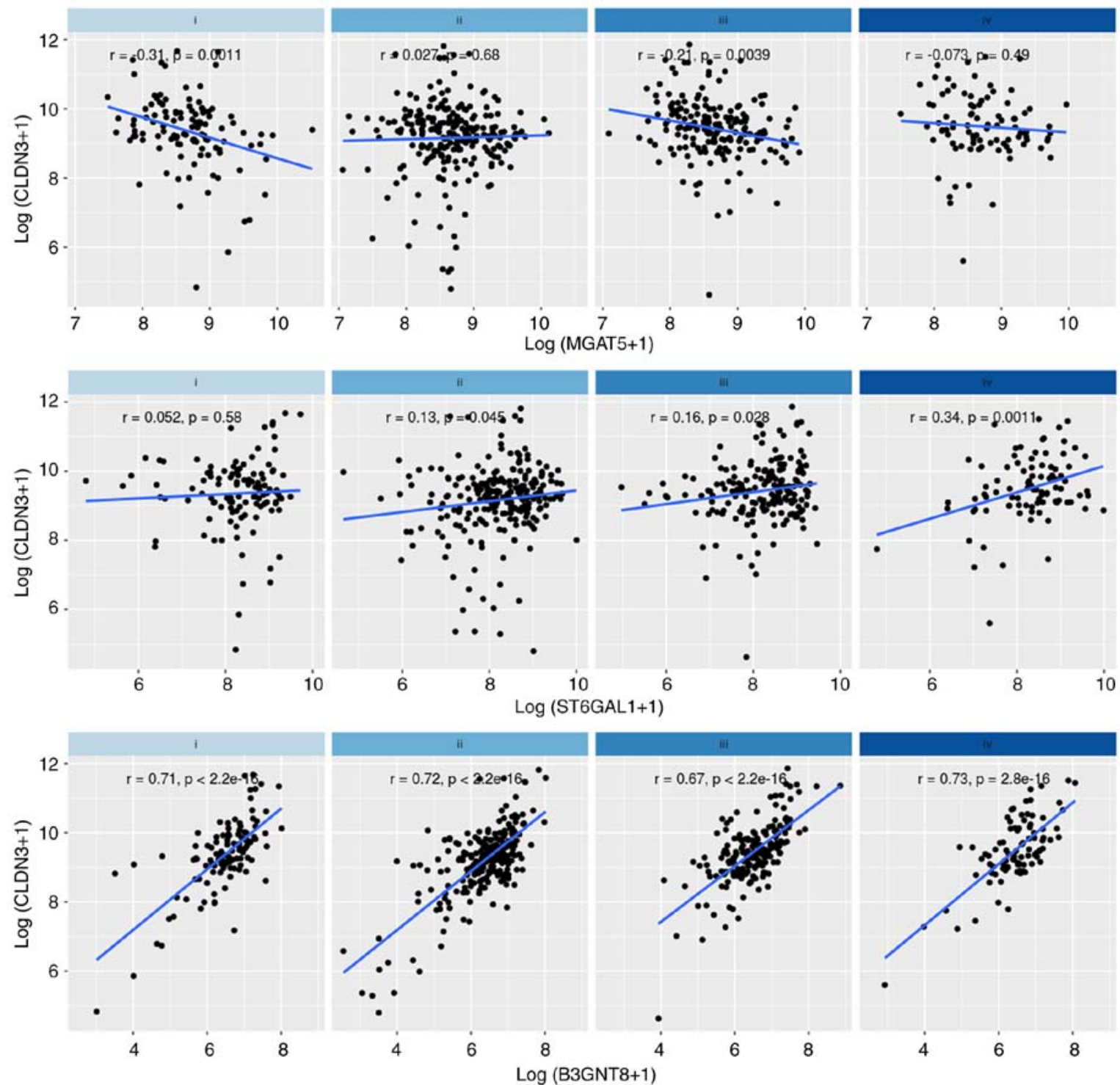

Figure 5. Correlation analyses between CLDN3 and MGAT5, ST6GAL1, and B3GNT8 in each of the colorectal cancer (CRC) stages. The correlation graphs represent the relationship between gene expression data from The Cancer Genome Atlas (TCGA) project database that were stratified based on the staging of the disease. $C L D N 3$, gene encoding claudin-3; MGAT5, $\alpha$-mannoside $\beta$-1,6-N-acetylglucosaminyltransferase; ST6GAL1, ST6 $\beta$-galactoside $\alpha$-2,6-sialyltransferase; $B 3 G N T 8, \beta-1,3-N$-acetylglucosaminyltransferase 8 .

revealed that tunicamycin treatment did not have a significant effect on the permeability of ruthenium red, which permeated the paracellular region of the monolayers. However, tunicamycin treatment did appear to promote tight cell-cell contacts (Fig. 2E, lower panel). Taken together, these data suggest that $N$-glycans are important for regulating both the claudin-3 levels and the stability of the TJs.

Inhibition of $N$-glycan biosynthesis affects RTK phosphorylation in CRC cells. Previous studies have demonstrated that claudin levels are regulated by signaling pathways activated through transmembrane glycoproteins, such as RTKs $(12,24)$. Our evaluation of the effects of tunicamycin on the phosphorylation levels of two RTKs (EGFR and IGF1R) revealed that inhibition of $\mathrm{N}$-glycan biosynthesis decreased the phosphorylation levels of both receptors (Fig. 3A), indicating that modulation of RTK function by $N$-glycans may impact both receptor functionality and related signaling pathways.
Inhibition of RTK signaling affects the levels of claudin-3. Inhibition of $N$-glycan biosynthesis has broad effects on physiology irrespective of effects on RTKs; therefore, we evaluated the effects of RTK-specific inactivation on claudin-3 levels. HCT-116 cells were treated for $24 \mathrm{~h}$ with different concentrations of PD153035 (an EGFR inhibitor) or OSI906 (an IGF1R inhibitor). These treatments decreased EGFR and IGF1R phosphorylation levels and reduced the claudin-3 levels (Fig. 3B and C), indicating that the specific inactivation of EGFR or IGF1R signaling decreased claudin-3 levels. The RTK-related signaling mechanism involved was investigated by using specific inhibitors of PLC (U73122), MAPK (PD98059), AKT (LY294002), and STAT3 (STA-21). PLC and STAT3 inhibition, but not MAPK and AKT inhibition, significantly reduced the claudin-3 levels (Fig. 3E-H). Concomitant treatment with U73122 and STA-21 did not increase the inhibitory effect on claudin-3 levels (Fig. 3I). Interestingly, inhibition of PKA (which is not related to RTK signaling) 

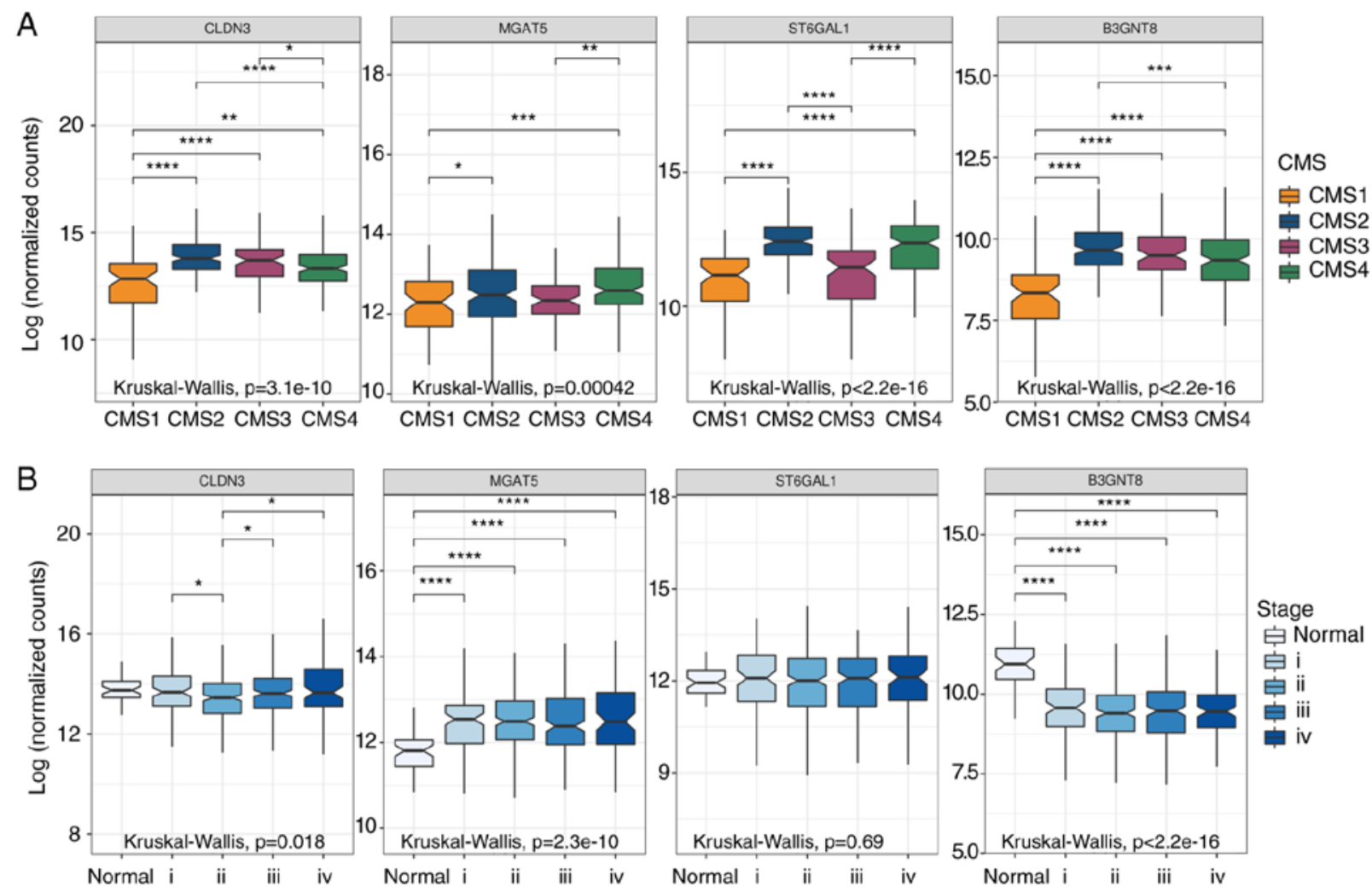

Figure 6. Expression of CLDN3, and $N$-glycan-related genes (MGAT5, ST6GAL1, and B3GNT8) in samples from patients with colorectal cancer (CRC). Box graphs represents absolute values of gene expression from tumors (n=644) and normal tissue samples (n=51) accessed in The Cancer Genome Atlas (TCGA) database. (A) Colorectal cancer consensus molecular subtypes (CMS). CMS1 n=90; CMS2 n=242; CMS3 n=78; CMS4 n=165; and (B) colorectal cancer disease stages (i, ii, iii, iv). Only significant differences are highlighted. The symbols correspond to the Dunn's rank sum test P-values adjusted with Hochberg's multiple comparisons correction ${ }^{*}$ Padj $<0.05 ;{ }^{* *}$ Padj $<0.01 ;{ }^{* * *}$ Padj $<0.001 ;{ }^{* * * *}$ Padj $<0.0001$. CLDN3, gene encoding claudin-3; MGAT5, $\alpha$-mannoside $\beta$-1,6- $N$-acetylglucosaminyltransferase; ST6GAL1, ST6 $\beta$-galactoside $\alpha$-2,6-sialyltransferase; $B 3 G N T 8, \beta-1,3-N$ - $\alpha$ cetylglucosaminyltransferase 8 .

by $\mathrm{H}-89$ also led to a significant reduction of claudin-3 levels (Fig. 3H). Collectively, these results showed that a complex regulatory network influences the protein levels of claudin-3 and may not be related exclusively to RTKs. These data also suggest that the regulation of claudin-3 levels due to modulation of RTK activity, including changes in its $\mathrm{N}$-glycosylation pattern, may be associated with disturbances in the PLC and STAT3 pathways.

CLDN3 and B3GNT8 expression levels correlate positively in $C R C$. Previous studies have shown that changes in $N$-glycosylation affect the functionality of RTKs (17-19), suggesting a possible correlation between CLDN3 expression and transcript levels of $N$-glycan-related genes in CRC. We investigated three $N$-glycogenes (Fig. S1). The first was MGAT5, the gene encoding human $N$-acetylglucosaminyltransferase $\mathrm{V}$ (MGAT5 or GnT-V) that synthesizes the $\beta 1,6-$ GlcNAc branching $N$-glycan structures widely associated with a malignant phenotype (25). The second was B3GNT8, the gene encoding human UDP-GlcNAc: $\beta$ Gal $\beta-1,3-N$-acetylgl ucosaminyltransferase 8 , the enzyme involved in the biosynthesis of poly- $N$-acetyllactosamine chains on $\beta 1,6$-branched $N$-glycan. This branching increases the reactivity to L-PHA when the enzyme is overexpressed in CRC cells, suggesting a potential involvement in malignancy (26). The third gene was ST6GAL1, which encodes the human ST6 $\beta$-galactosamide $\alpha$-2,6-sialyltranferase 1 , a sialyltransferase that adds an $\alpha$-2-6-linked sialic acid to the $N$-glycan and is upregulated in CRC $(27,28)$. Our in silico approach revealed a robust positive correlation between $C L D N 3$ and B3GNT8 expression levels in all four CMS and in all stages of CRC (Figs. 4 and 5). A weaker positive correlation was also observed between $C L D N 3$ and ST6GAL1 expression in stages II, III, and IV of CRC (Fig. 5). Surprisingly, a negative correlation was observed between CLDN3 and MGAT5 expression levels in stages I and III, as well as in CMS2 (Figs. 4 and 5). Since $N$-glycans can regulate RTK activity, these results support the possibility of a regulatory mechanism that interconnects RTKs, CLDN3, and $N$-glycan-related glycogenes.

CLDN3 and N-glycan-related glycogenes show similar expression patterns within molecular subtypes of colorectal cancer. We also investigated the expression profile of CLDN3 and $N$-glycogenes in different CRC stages and CMS. The in silico analysis comparing the molecular subtypes to each other showed that CMS1 is a subtype that exhibits low expression levels of CLDN3, MGAT5, ST6GAL1, and B3GNT8 when compared to the other subtypes, while CMS2 is a subtype that exhibits high expression levels of CLDN3, ST6GAL1, and B3GNT8 when compared to the other subtypes (Fig. 6, upper panel). In addition, all analyzed genes had higher levels in CMS2 than in CMS1. Upregulation of ST6GAL1 is frequently observed in CRC samples $(29,30)$, in agreement with significantly higher expression levels of ST6GAL1 in CMS2, the 
most frequent subtype (Fig. 6, upper panel). Our analysis of the expression of the same genes of interest (CLDN3, and $N$-glycan-related genes) in the different stages of CRC (Fig. 6, lower panel) revealed downregulation of CLDN3 in stage II, and also downregulation of B3GNT8 in all stages of cancer (Fig. 6, lower panel). Interestingly, we observed that MGAT5 was significantly upregulated in CRC, even in the early stages of disease (I and II) (Fig. 6, lower panel), suggesting that MGAT5 expression could be a potential biomarker of CRC.

\section{Discussion}

A stable apical junctional complex (AJC) has been considered to be a suppressor of carcinoma progression due to its role in the maintenance of apical-basolateral polarity, intercellular adhesion, and epithelial architecture $(31,32)$. The dysregulation of this protein complex is correlated with a malignant phenotype and a poor clinical outcome $(12,33,34)$. The regulatory role of $\mathrm{N}$-glycans in the stability and function of AJC has been demonstrated $(16,35)$, but few studies have been dedicated specifically to investigating the role of $N$-glycosylation on TJ function. Here, we demonstrated that the inhibition of the $\mathrm{N}$-glycan biosynthesis pathway leads to a subcellular redistribution of claudin-3 and decreases its levels in colorectal cancer (CRC) HCT-116 cells (undifferentiated phenotype). Changes in both protein levels (overexpression or downregulation) and subcellular localization of different claudins may lead to the loss of TJ functionality $(12,36,37)$. We previously reported that claudin-3 overexpression in HT-29 cells (moderately differentiated CRC cells) increases the malignancy potential and affects the mechanisms of paracellular flux control (12).

In the present work, we observed that inhibition of $N$-glycan biosynthesis by tunicamycin led to a decrease in claudin-3 levels in HCT-116 cells, which is a cell line that endogenously presents high levels of this protein. However, tunicamycin did not restore the flow of ruthenium red dye through the TJs. We suspect that this finding may be related to the undifferentiated phenotype of these cells, where the decrease in claudin-3 levels was not sufficient to completely restore TJ-mediated permeability. We did, however, observe that tunicamycin led to the establishment of tighter cell-cell contacts, which may contribute to a more differentiated phenotype (23) and to a decrease in invasiveness (38). Moreover, tunicamycin also promoted an increase in claudin-3 levels on the cellular membrane.

The tighter cell-cell contact can be explained, at least in part, by the protein composition of TJ strands. Changes in claudin levels also facilitate the incorporation of other isoforms to compose their oligomers, which may interfere in both barrier and channel functions of the tight junctions (39). Claudin-3, for example, can interact with claudins 1,4 , and 8 to form oligomers, besides being able to interact with claudins 1,2 , and 5 from adjacent cells $(40,41)$. A previous study that analyzed the expression of several claudin isoforms in normal and tumor tissues identified mechanisms that may simultaneously regulate $C L D N 3, C L D N 4$, and $C L D N 7$ and lead to very similar expression patterns of these genes (42). Therefore, we should not disregard the possibility of variations in the levels of other isoforms of claudin in the context of the decreased claudin-3 that was observed in the present study.
The influence of receptor tyrosine kinases (RTKs) on the control of TJ stability is already known (13-15); however, the regulatory role of $N$-glycans in this process remains poorly understood. Here, we found that epidermal growth factor receptor (EGFR) and insulin-like growth factor 1 receptor (IGF1R) deglycosylation induced by treatment with tunicamycin led to a decrease in the phosphorylation levels of both receptors. The specific inhibition of EGFR or IGF1R also decreased both their phosphorylation and the claudin-3 protein levels. These findings show that RTK-related downstream signaling pathways regulates the content of claudin-3 in HCT-116 cells. Although we identified RTK-related signaling pathways (PLC and STAT3) that regulate claudin-3 levels in CRC HCT-116 cells, the findings did not reveal the mechanism that integrates RTKs, glycogenes, and claudin-3 levels. Our ongoing studies are addressing this issue.

The differential levels of claudins in distinct carcinomas have been previously reported (43). A gene expression-based study identified a molecular subtype of breast cancer characterized by low levels of mRNA coding for claudins, referred to as the claudin-low molecular subtype (44). Interestingly, while the low expression of CLDN3 in this subtype was related to worse overall survival (44), other carcinomas, such as colorectal, breast, gastric, ovary, and pancreas carcinomas, have shown increased levels of various claudins (45), as well as being related to a poor prognosis (46). Indeed, the expression levels of cancer-related genes have been extensively used as a parameter to determine tumor molecular subtypes related to distinct clinical outcomes $(47,48)$.

Regarding CRC, the recent gene profiling-based stratification system, which has identified consensus molecular subtypes with prognostic and predictive differences, represents a novel classification method that can improve clinical practice (49). In our study, we analyzed the overall survival of CRC patients according to the expression levels of $C L D N 3$. Low expression levels of $C L D N 3$ in the CMS2 and CMS3 subtypes improved the patients' long-term survival. Recently, similar results were reported regarding the identification of intra-CMS subgroups using the expression levels of claudins, thereby corroborating the use of this strategy for the identification of molecular subtypes (50). Our findings also revealed that an integrated analysis of functionally related genes in a particular cellular event (e.g., TJ stability regulation) should be explored as a useful tool to better understand the specific alterations in each CMS.

We also found that the potential functional relationship between CLDN3, MGAT5, ST6GAL1, and B3GNT8 could be subtype-specific, since we observed that these genes display higher expression levels in the CMS2 than in the CMS1 subtype. These findings also suggest that multidimensional analyses that considering the different stages of CRC, and especially molecular subtypes, are crucial for the identification of regulatory mechanisms that rely on the integrated participation of several genes.

The differential gene expression seen among these CMSs can be assumed to have biological significance corresponding to their respective protein levels; however, the existence of discrepancies cannot be disregarded between mRNA levels and protein expressions attributable to other levels of 
regulation (51). Nevertheless, this correlation appears to be quite reliable within distinct biological groups (52).

One important issue in the classification of cancers into molecular subtypes concerns the limitations imposed by tumor heterogeneity. Intratumoral heterogeneity has challenged the actual classification of CRC because the region of the tumor where the sample is taken for molecular profiling analysis could obscure the tumor classification (53). Nevertheless, other authors have argued that tumor-intrinsic subtyping captures the vast majority of biological diversity (54). Pioneering translational research in colorectal cancer has shown that a specific molecular subtype of CRC, called CCS3, is resistant to anti-EGFR therapy in a clinical setting, independent of RAS mutation status, the classical determinant for therapy response (55).

Encouraging data have recently clarified this issue, as no differences were observed in the survival of KRAS/BRAF wild-type patients treated with cetuximab whose tumors had been classified as mesenchymal-like (CMS4) (56). This confirms the importance of discovering the molecular identities and new targets if improvements in the efficacy of therapies against CRC are to be achieved. Here, we identified an intra-CMS2 and intra-CMS3 subgroups that show significant differences in terms of the patients' long-term survival based on the expression pattern of CLDN3. We also demonstrated that the inhibition of $N$-glycan biosynthesis compromises RTK activation, thereby corroborating previous data suggesting $N$-glycosylation as a promising target in cancer therapy (57-59).

Aberrant $N$-glycosylation in cancer cells has been reported previously (60) and is regulated by changes in enzyme levels that make up the glycosylation machinery $(48,61)$, among other factors. Alterations in glycan structures, as well as in the enzymes responsible for them, are accepted as possible biomarkers in cancer (62-64). For example, MGAT5 and $\beta 1,6$-branched $N$-glycans are useful markers for predicting the aggressive phenotype in CRC tumors $(65,66)$. Here, we observed that MGAT5 was upregulated in CRC samples, even in those from patients with early stages of disease. This result suggests that the overexpression of the MGAT5 gene could be a potential CRC biomarker, once the $N$-glycan-related gene expression profile has also been used to identify CRC molecular biomarkers (48).

In conclusion, the data we have presented here suggest a modulatory role of $N$-glycosylation in RTK functionality and in the regulation of claudin-3 protein levels. We also demonstrated that the expression analysis of $C L D N 3$ and $N$-glycan-related genes could be clinically useful for determining relevant CRC subtypes, as well as for identifying potential glycobiomarkers. Our findings provide insights into how the dysregulation of claudin-3 occurs in CRC.

\section{Acknowledgements}

We are grateful to all members of the laboratory, particularly to Annie Cristhine Moraes Sousa-Squiavinato, and Bruna dos Santos Mendonça, for assistance with relevant suggestions.

\section{Funding}

This work was funded by Ministério da Saúde, Coordenação de Aperfeiçoamento de Pessoal de Nível Superior (CAPES),
Fundação de Amparo à Pesquisa do Estado do Rio de Janeiro (FAPERJ), and Conselho Nacional de Desenvolvimento Científico e Tecnológico (CNPq - grant no. 404052/2016-9).

\section{Availability of data and materials}

The data that support the findings of this study are available from the corresponding author upon reasonable request.

\section{Authors' contributions}

This study was designed and supervised by JCMDF Jr. AGP performed experiments and drafted the manuscript. JADC, WFDS, MDSF and CAFN performed experiments. MB, CADL and PTSS contributed in collecting and analyzing data. IMDO and PVF collected patient samples and performed experiments. JAMD co-supervised the experiments. All authors read and approved the manuscript and agree to be accountable for all aspects of the research in ensuring that the accuracy or integrity of any part of the work are appropriately investigated and resolved.

\section{Ethics approval and consent to participate}

The study was approved by the Ethics Committee of the National Cancer Institute (INCA) (Rio de Janiero, Brazil). Written informed consent was obtained from all patients.

\section{Patient consent for publication}

Not applicable.

\section{Competing interests}

The authors have declared that no competing interest exists.

\section{References}

1. IJspeert JE, Vermeulen L, Meijer GA and Dekker E: Serrated neoplasia-role in colorectal carcinogenesis and clinical implications. Nat Rev Gastroenterol Hepatol 12: 401-409, 2015.

2. Vogelstein B, Papadopoulos N, Velculescu VE, Zhou S, Diaz LA Jr and Kinzler KW: Cancer genome landscapes. Science 339: 1546-1558, 2013.

3. Fessler E, Drost J, van Hooff SR, Linnekamp JF, Wang X, Jansen M, De Sousa E Melo F, Prasetyanti PR, IJspeert JE, et al: TGF $\beta$ signaling directs serrated adenomas to the mesenchymal colorectal cancer subtype. EMBO Mol Med 8: 745-760, 2016.

4. Guinney J, Dienstmann R, Wang X, de Reyniès A, Schlicker A, Soneson C, Marisa L, Roepman P, Nyamundanda G, Angelino P, et al: The consensus molecular subtypes of colorectal cancer. Nat Med 21: 1350-1356, 2015.

5. Bramsen JB, Rasmussen MH, Ongen H, Mattesen TB, Ørntoft MW, Árnadóttir SS, Sandoval J, Laguna T, Vang S, $\emptyset$ ster B, et al: Molecular-subtype-specific biomarkers improve prediction of prognosis in colorectal cancer. Cell Rep 19: 1268-1280, 2017.

6. Gehren AS, Rocha MR, de Souza WF and Morgado-Díaz JA: Alterations of the apical junctional complex and actin cytoskeleton and their role in colorectal cancer progression. Tissue Barriers 3: e1017688, 2015.

7. Lingaraju A, Long TM, Wang Y, Austin JR II and Turner JR: Conceptual barriers to understanding physical barriers. Semin Cell Dev Biol 42: 13-21, 2015.

8. Zihni C, Mills C, Matter K and Balda MS: Tight junctions: From simple barriers to multifunctional molecular gates. Nat Rev Mol Cell Biol 17: 564-580, 2016. 
9. de Oliveira SS, de Oliveira IM,De Souza W and Morgado-DíazJA Claudins upregulation in human colorectal cancer. FEBS Lett 579: 6179-6185, 2005.

10. Krug SM, Schulzke JD and Fromm M: Tight junction, selective permeability, and related diseases. Semin Cell Dev Biol 36: 166-176, 2014.

11. Wang Y, Sun T, Sun H, Yang S, Li D and Zhou D: SCF/C-Kit/JNK/AP-1 signaling pathway promotes claudin-3 expression in colonic epithelium and colorectal carcinoma. Int J Mol Sci 18: 765, 2017.

12. de Souza WF, Fortunato-Miranda N, Robbs BK, de Araujo WM, de-Freitas-Junior JC, Bastos LG, Viola JP and Morgado-Díaz JA: Claudin-3 overexpression increases the malignant potential of colorectal cancer cells: Roles of ERK1/2 and PI3K-Akt as modulators of EGFR signaling. PLoS One 8: e74994, 2013.

13. Singh AB and Harris RC: Epidermal growth factor receptor activation differentially regulates claudin expression and enhances transepithelial resistance in madin-darby canine kidney cells. J Biol Chem 279: 3543-3552, 2004.

14. Ikari A, Sato T, Watanabe R, Yamazaki Y and Sugatani J: Increase in claudin-2 expression by an EGFR/MEK/ERK/c-fos pathway in lung adenocarcinoma A549 cells. Biochim Biophys Acta 1823: 1110-1118, 2012.

15. Campbell HK, Maiers JL and DeMali KA: Interplay between tight junctions \& adherens junctions. Exp Cell Res 358: 39-44, 2017.

16. Nita-Lazar M, Rebustini I, Walker J and Kukuruzinska MA: Hypoglycosylated E-cadherin promotes the assembly of tight junctions through the recruitment of PP2A to adherens junctions. Exp Cell Res 316: 1871-1884, 2010.

17. Fernandes H, Cohen S and Bishayee S: Glycosylation-induced conformational modification positively regulates receptorreceptor association: A study with an aberrant epidermal growth factor receptor (EGFRvIII/DeltaEGFR) expressed in cancer cells. J Biol Chem 276: 5375-5383, 2001.

18. Whitson KB, Whitson SR, Red-Brewer ML, McCoy AJ, Vitali AA, Walker F, Johns TG, Beth AH and Staros JV: Functional effects of glycosylation at asn-579 of the epidermal growth factor receptor. Biochemistry 44: 14920-14931, 2005.

19. Kaszuba K, Grzybek M, Orłowski A, Danne R, Róg T, Simons K, Coskun Ü and Vattulainen I: N-Glycosylation as determinant of epidermal growth factor receptor conformation in membranes. Proc Natl Acad Sci USA 112: 4334-4339, 2015.

20. Lopez Sambrooks C, Baro M, Quijano A, Narayan A, Cui W, Greninger P, Egan R, Patel A, Benes CH, Saltzman WM and Contessa JN: Oligosaccharyltransferase inhibition overcomes therapeutic resistance to EGFR tyrosine kinase inhibitors. Cancer Res 78: 5094-5106, 2018.

21. Lau KS, Partridge EA, Grigorian A, Silvescu CI, Reinhold VN, Demetriou M and Dennis JW: Complex N-glycan number and degree of branching cooperate to regulate cell proliferation and differentiation. Cell 129: 123-134, 2007.

22. Colaprico A, Silva TC, Olsen C, Garofano L, Cava C, Garolini D, Sabedot TS, Malta TM, Pagnotta SM, Castiglioni I, et al: TCGAbiolinks: An R/bioconductor package for integrative analysis of TCGA data. Nucleic Acids Res 44: e71, 2016.

23. de Freitas Junior JC, Silva BR, de Souza WF, de Araújo WM, Abdelhay ES and Morgado-Díaz JA: Inhibition of N-linked glycosylation by tunicamycin induces E-cadherin-mediated cell-cell adhesion and inhibits cell proliferation in undifferentiated human colon cancer cells. Cancer Chemother Pharmacol 68: 227-238, 2011.

24. Peter Y, Comellas A, Levantini E, Ingenito EP and Shapiro SD: Epidermal growth factor receptor and claudin-2 participate in A549 permeability and remodeling: Implications for non-small cell lung cancer tumor colonization. Mol Carcinog 48: 488-497, 2009.

25. Taniguchi $\mathrm{N}$ and Korekane $\mathrm{H}$ : Branched N-glycans and their implications for cell adhesion, signaling and clinical applications for cancer biomarkers and in therapeutics. BMB Rep 44: 772-781, 2011.

26. Ishida H, Togayachi A, Sakai T, Iwai T, Hiruma T, Sato T, Okubo R, Inaba $\mathrm{N}$, Kudo $\mathrm{T}$, Gotoh $\mathrm{M}$, et al: A novel beta1,3-N-acetylglucosaminyltransferase (beta3Gn-T8), which synthesizes poly- $\mathrm{N}$-acetyllactosamine, is dramatically upregulated in colon cancer. FEBS Lett 579: 71-78, 2005.

27. Dall'Olio F, Malagolini N, di Stefano G, Minni F, Marrano D and Serafini-Cessi F: Increased CMP-NeuAc:Gal beta 1,4GlcNAc-R alpha 2,6 sialyltransferase activity in human colorectal cancer tissues. Int J Cancer 44: 434-439, 1989.
28. Petretti T, Kemmner W, Schulze B and Schlag PM: Altered mRNA expression of glycosyltransferases in human colorectal carcinomas and liver metastases. Gut 46: 359-366, 2000.

29. Dall'Olio F, Chiricolo M, Ceccarelli C, Minni F, Marrano D and Santini D: Beta-galactoside alpha2,6 sialyltransferase in human colon cancer: Contribution of multiple transcripts to regulation of enzyme activity and reactivity with sambucus nigra agglutinin. Int J Cancer 88: 58-65, 2000.

30. Dall'Olio F, Chiricolo M, Mariani E and Facchini A: Biosynthesis of the cancer-related sialyl-alpha 2,6-lactosaminyl epitope in colon cancer cell lines expressing beta-galactoside alpha 2,6-sialyltransferase under a constitutive promoter. Eur J Biochem 268: 5876-5884, 2001.

31. Royer C and Lu X: Epithelial cell polarity: A major gatekeeper against cancer? Cell Death Differ 18: 1470-1477, 2011.

32. Halaoui R and McCaffrey L: Rewiring cell polarity signaling in cancer. Oncogene 34: 939-950, 2015.

33. Bouchagier KA, Assimakopoulos SF, Karavias DD, Maroulis I, Tzelepi V, Kalofonos H, Karavias DD, Kardamakis D, Scopa CD and Tsamandas AC: Expression of claudins-1, -4, -5, -7 and occludin in hepatocellular carcinoma and their relation with classic clinicopathological features and patients' survival. In Vivo 28: 315-326, 2014.

34. Katayama A, Handa T, Komatsu K, Togo M, Horiguchi J, Nishiyama M and Oyama T: Expression patterns of claudins in patients with triple-negative breast cancer are associated with nodal metastasis and worse outcome. Pathol Int 67: 404-413, 2017.

35. Pinho SS, Figueiredo J, Cabral J, Carvalho S, Dourado J, Magalhães A, Gärtner F, Mendonfa AM, Isaji T, Gu J, et al: E-cadherin and adherens-junctions stability in gastric carcinoma: Functional implications of glycosyltransferases involving $\mathrm{N}$-glycan branching biosynthesis, $\mathrm{N}$-acetylglucosaminyltransferases III and V. Biochim Biophys Acta 1830: 2690-2700, 2013.

36. Bücker R, Krug SM, Fromm A, Nielsen HL, Fromm M, Nielsen H and Schulzke JD: Campylobacter fetus impairs barrier function in HT-29/B6 cells through focal tight junction alterations and leaks. Ann N Y Acad Sci 1405: 189-201, 2017.

37. Zeissig S, Bürgel N, Günzel D, Richter J, Mankertz J, Wahnschaffe U,Kroesen AJ,Zeitz M,Fromm M and Schulzke JD: Changes in expression and distribution of claudin 2,5 and 8 lead to discontinuous tight junctions and barrier dysfunction in active crohn's disease. Gut 56: 61-72, 2007.

38. Nami B, Donmez H and Kocak N: Tunicamycin-induced endoplasmic reticulum stress reduces in vitro subpopulation and invasion of $\mathrm{CD} 44^{+} / \mathrm{CD} 24^{-}$phenotype breast cancer stem cells. Exp Toxicol Pathol 68: 419-426, 2016.

39. Capaldo CT and Nusrat A: Claudin switching: Physiological plasticity of the tight junction. Semin Cell Dev Biol 42: 22-29, 2015.

40. Findley MK and Koval M: Regulation and roles for claudin-family tight junction proteins. IUBMB Life 61: 431-437, 2009.

41. Koval M: Differential pathways of claudin oligomerization and integration into tight junctions. Tissue Barriers 1: e24518, 2013.

42. Hewitt KJ, Agarwal R and Morin PJ: The claudin gene family: Expression in normal and neoplastic tissues. BMC Cancer 6: 186, 2006.

43. Kwon MJ: Emerging roles of claudins in human cancer. Int J Mol Sci 14: 18148-18180, 2013.

44. Dias K, Dvorkin-Gheva A, Hallett RM, Wu Y, Hassell J, Pond GR, Levine M, Whelan T and Bane AL: Claudin-low breast cancer; clinical \& pathological characteristics. PLoS One 12: e0168669, 2017.

45. Oliveira SS and Morgado-Díaz JA: Claudins: Multifunctional players in epithelial tight junctions and their role in cancer. Cell Mol Life Sci 64: 17-28, 2007.

46. Iacobuzio-Donahue CA, Maitra A, Shen-Ong GL, van Heek T, Ashfaq R, Meyer R, Walter K, Berg K, Hollingsworth MA, Cameron $\mathrm{JL}$, et al: Discovery of novel tumor markers of pancreatic cancer using global gene expression technology. Am J Pathol 160: 1239-1249, 2002.

47. Levine EA, Votanopoulos KI, Qasem SA, Philip J, Cummins KA, Chou JW, Ruiz J, D'Agostino R, Shen P and Miller LD: Prognostic molecular subtypes of low-grade cancer of the appendix. J Am Coll Surg 222: 493-503, 2016.

48. Ashkani J and Naidoo KJ: Glycosyltransferase gene expression profiles classify cancer types and propose prognostic subtypes. Sci Rep 6: 26451, 2016. 
49. Thanki K, Nicholls ME, Gajjar A, Senagore AJ, Qiu S, Szabo C, Hellmich MR and Chao C: Consensus molecular subtypes of colorectal cancer and their clinical implications. Int Biol Biomed J 3: 105-111, 2017

50. Cherradi S, Martineau P, Gongora C and Del Rio M: Claudin gene expression profiles and clinical value in colorectal tumors classified according to their molecular subtype. Cancer Manag Res 11: 1337-1348, 2019.

51. Vogel C and Marcotte EM: Insights into the regulation of protein abundance from proteomic and transcriptomic analyses. Nat Rev Genet 13: 227-232, 2012.

52. Koussounadis A, Langdon SP, Um IH, Harrison DJ and Smith VA: Relationship between differentially expressed mRNA and mRNA-protein correlations in a xenograft model system. Sci Rep 5: 10775, 2015.

53. Dunne PD, McArt DG, Bradley CA, O'Reilly PG, Barrett HL, Cummins R, O'Grady T, Arthur K, Loughrey MB, Allen WL, et al: Challenging the cancer molecular stratification dogma: Intratumoral heterogeneity undermines consensus molecular subtypes and potential diagnostic value in colorectal cancer. Clin Cancer Res 22: 4095-4104, 2016.

54. Prat A, Pineda E, Adamo B, Galván P, Fernández A, Gaba L, Díez M, Viladot M, Arance A and Muñoz M: Clinical implications of the intrinsic molecular subtypes of breast cancer. Breast 24 (Suppl 2): S26-S35, 2015.

55. De Sousa E Melo F, Wang X, Jansen M, Fessler E, Trinh A de Rooij LP, de Jong JH, de Boer OJ, van Leersum R, et al: Poor-prognosis colon cancer is defined by a molecularly distinct subtype and develops from serrated precursor lesions. Nat Med 19: 614-618, 2013.

56. Trinh A, Trumpi K, De Sousa E Melo F, Wang X, de Jong JH, Fessler E, Kuppen PJ, Reimers MS, Swets M, et al: Practical and robust identification of molecular subtypes in colorectal cancer by immunohistochemistry. Clin Cancer Res 23: 387-398, 2017.

57. Carvalho S, Reis CA and Pinho SS: Cadherins glycans in cancer: Sweet players in a bitter process. Trends Cancer 2: 519-531, 2016.

58. Contessa JN, Bhojani MS, Freeze HH, Ross BD, Rehemtulla A and Lawrence TS: Molecular imaging of N-linked glycosylation suggests glycan biosynthesis is a novel target for cancer therapy. Clin Cancer Res 16: 3205-3214, 2010
59. de Freitas Junior JC and Morgado-Díaz JA: The role of N-glycans in colorectal cancer progression: Potential biomarkers and therapeutic applications. Oncotarget 7: 19395-19413, 2016.

60. Anugraham M, Jacob F, Nixdorf S, Everest-Dass AV, Heinzelmann-Schwarz V and Packer NH: Specific glycosylation of membrane proteins in epithelial ovarian cancer cell lines: Glycan structures reflect gene expression and DNA methylation status. Mol Cell Proteomics 13: 2213-2232, 2014.

61. Kannagi R, Yin J, Miyazaki K and Izawa M: Current relevance of incomplete synthesis and neo-synthesis for cancer-associated alteration of carbohydrate determinants-Hakomori's concepts revisited. Biochim Biophys Acta 1780: 525-531, 2008.

62. Meany DL and Chan DW: Aberrant glycosylation associated with enzymes as cancer biomarkers. Clin Proteomics 8: 7 , 2011.

63. Liu L, Yan B, Huang J, Gu Q, Wang L, Fang M, Jiao J and Yue X: The identification and characterization of novel N-glycan-based biomarkers in gastric cancer. PLoS One 8: e77821, 2013.

64. Qin R, Zhao J, Qin W, Zhang Z, Zhao R, Han J, Yang Y, Li L, Wang X, Ren S, et al: Discovery of non-invasive glycan biomarkers for detection and surveillance of gastric cancer. J Cancer 8: 1908-1916, 2017.

65. Kim YS, Ahn YH, Song KJ, Kang JG, Lee JH, Jeon SK, Kim HC, Yoo JS and Ko JH: Overexpression and $\beta-1,6-\mathrm{N}$-acetylglucosam inylation-initiated aberrant glycosylation of TIMP-1: A 'double whammy' strategy in colon cancer progression. J Biol Chem 287: 32467-32478, 2012.

66. Murata K, Miyoshi E, Kameyama M, Ishikawa O, Kabuto T, Sasaki Y, Hiratsuka M, Ohigashi $\mathrm{H}$, Ishiguro S, Ito S, et al: Expression of $\mathrm{N}$-acetylglucosaminyltransferase $\mathrm{V}$ in colorectal cancer correlates with metastasis and poor prognosis. Clin Cancer Res 6: 1772-1777, 2000

This work is licensed under a Creative Commons Attribution-NonCommercial-NoDerivatives 4.0 International (CC BY-NC-ND 4.0) License. 